\title{
The COVID-19 epidemic in Brazil: how statistics education may contribute to unravel the reality behind the charts
}

\author{
Alexandre Sousa da Silva ${ }^{1}$ (D) - Maria Tereza Serrano Barbosa ${ }^{1}$ (D) . \\ Luciane de Souza Velasque $^{1}$ (D) . Davi da Silveira Barroso Alves ${ }^{1}$ (D) . \\ Marcos Nascimento Magalhães ${ }^{2}$ (D)
}

Accepted: 13 September 2021/ Published online: 14 October 2021

(C) The Author(s), under exclusive licence to Springer Nature B.V. 2021

\begin{abstract}
The world is now facing the most severe health, social, and economic event of the last hundred years, which has made the need to acquire statistical thinking to interpret the information disseminated on a daily basis by the media clear to society. This article proposes a discussion on the role that statistics education might play in supporting the acquisition of such knowledge, contributing to the development of critical citizens, aware of their social responsibility. In this context, we present examples of curves and other charts to demonstrate how to use the several levels defined by experts in reading and interpreting the charts. At a more advanced level, these examples will allow discussion on the impacts of this epidemic on the most vulnerable population in Brazil. The charts presented reveal a great regional inequality, suggesting that mortality due to the virus is distinguished by region and micro-region when considering access to hospital beds. The examples signpost ways for educators to be able to develop projects or research based on the discussion on the reality of the pandemic, the necessary public policies, and how political coordination grounded on science and on a humanitarian vision would have mitigated the Brazilian tragedy.
\end{abstract}

Keywords Statistics education · COVID-19 $\cdot$ Inequality $\cdot$ Charts

\section{Introduction}

The COVID-19 pandemic is the most severe humanitarian crisis in the past hundred years worldwide. The crisis has required a global effort from the most diverse sectors of society, from scientists to political leaders, to study, reflect upon, and anticipate how the world, the countries, housing, work, and study environments could be protected. The development of vaccines in less than a year was a great victory for science and brought hope to humanity.

Placing the challenges posed by the pandemic into context and taking into account Brazil's reality, in this article, we intend to call attention to the importance of statistical

Alexandre Sousa da Silva

alexandre.silva@uniriotec.br

Departamento de Métodos Quantitativos, EM-UNIRIO, Rio de Janeiro, RJ, Brazil

2 Departamento de Estatística, IME-USP, São Paulo, SP, Brazil 
literacy development to educate citizens to be mindful of their reality and engage in the fight for their rights. To illustrate, we present charts describing the epidemic curves that might expose and anticipate some of the impacts of the pandemic over the most vulnerable population due to the economic, social, and regional inequalities. Such charts, as well as a description of how they should be interpreted, are intended to encourage approaches aimed at developing projects and research actions in mathematics or statistics classes.

The basic knowledge regarding scientific methods, their basic assumptions, and the need to consider both ethical issues and the uncertainties arising from the results of the studies were brought to light during this pandemic. According to Bakker and Wagner (2020), the need to reinforce the population's statistical and mathematical literacy was emphasized as the media resorted to different types of representations to explain how momentous it was to curb the spread of the virus and how social distancing may help to keep the number of cases within the capacity of the health system.

Brazil has a publicly maintained health system, known as the Unified Health System, or "SUS" for its acronym in Portuguese. Despite this, the country had already accounted for over 194,000 deaths from COVID-19 by the end of December 2020. This number is potentially underestimated, because of the known lack of tests and insufficient access to health services by the population at large, as well as deaths possibly caused by COVID19 being reported as due to other causes. The Brazilian population has its national territory organized in five geographic regions. As a country of continental extensions with structural regional and economic inequalities resulting in contrasting health indicators (Szwarcwald et al., 2016), it has been under a sharp economic downturn for quite a few years. In addition to the massive struggle governors and mayors have been undergoing to provide for the SUS and curb the spread of COVID-19, several months after the first notified case, the President of Brazil, Jair Bolsonaro, made it very difficult to control the epidemic, stimulating the false and unscientific controversy between physical death and economic death, by publicly disagreeing with the stricter measures of social isolation enacted by several governors, indicating the existence of early treatment and making statements against vaccines. This behavior and the repeated and disastrous actions made by the president came to be cited by an editorial in a highly regarded medical journal (The Lancet, 2020). At the beginning of the epidemic, in less than a month, two health ministers who, against the president's wishes, tried to follow the guidelines issued by the World Health Organization (WHO) were removed from office. This lack of effective coordination contributed both to the high rates of contamination and mortality in Brazil, as well as to the delay of vaccination of its population. Unfortunately, the president still remained in the same inappropriate track, as noted in a recent correspondence by a Brazilian researcher, published in The Lancet (Hallal, 2021).

Indicators of access to basic sanitation, adequate housing conditions, and availability of public hospital beds showed that a considerable portion of the population in all federation units would be highly vulnerable to the effects of the epidemic. In a very recent paper, Ranzani et al. (2021) analyzed characteristics of patients admitted to hospital with COVID-19 in Brazil using data encompassing a 6-month period (Feb. 16 to Aug. 15, 2020, epidemiological weeks 8-33). Their study was about in-hospital mortality considering the whole country and its five regions and the analysis was stratified by age, intensive care unit admission, and respiratory support. In conclusion, they mention:

... we provide evidence of the impact of regional inequities on outcomes, and the collapse of the more fragile regional health systems during the pandemic. In-hospital 
mortality was high, even in younger age groups, particularly among patients who were mechanically ventilated. (p.11)

Thus, in Brazil, uncertainties arising from the severe impacts of this epidemic appear to be even greater and more urgent, which needs to be understood, studied, and discussed. " $\mathrm{O}$ Brasil não conhece o Brasil" [Brazil does not know its own self] is a phrase from a famous song by Aldir Blanc, a Brazilian composer victim of COVID-19. Based on this phrase, a discussion is herein proposed about the role that statistics education might play in minimizing such lack of knowledge, contributing to the development of critical citizens, mindful of their social responsibility, and active in monitoring their statistics and measures to protect the population.

We notice that greater mathematical, scientific, and statistical literacy may support the population in such discussion and, consequently, we further urge our society to increase the pressure for sensible public policies. A well-informed society is an important factor in putting pressure on governments, since, despite the results of several model simulations proposed in scientific publications and reproduced by the media, some heads of state, braced by their political-ideological positions, have remained reluctant to enact restrictive measures to delay the peak of the epidemic curve and prevent health systems from collapsing.

This paper is organized as follows: Section 2 makes a brief review of the literature focusing on representative authors in statistics literacy and in the reading and interpretation of graphs with a view to inform citizens; Section 3 exemplifies graphs that allow comparing COVID-19 death rates in Brazil and other countries, and explore how mortality rates in Brazil are geographically distributed and how such rates relate to indicators of social inequality; Section 4 provides some final considerations.

\section{Statistics teaching for citizens' education}

The overload of daily information with numbers and charts disseminated and discussed by physicians, epidemiologists, journalists, and managers portraying the tragic reality of the world, including Brazil, reinforces the need for some basic knowledge of statistics. Statistics educators refer to such knowledge as statistical literacy, which, according to Gal (2002), consists of:

a) people's ability to interpret and comprehensively evaluate statistical information, datarelated arguments, or stochastic phenomena, which may be encountered in diverse contexts, and when relevant;

b) the ability to discuss or communicate reactions to statistical information, such as the understanding of the meaning of the information, thoughts on the implications of such information, or concerns regarding the acceptability of the conclusions provided (p. 2-3)

In the same paper, Gal proposed a model for statistical literacy in a reading context. This context means the capacity to "comprehend, interpret, critically evaluate, and react to statistical messages encountered in reading contexts" (p. 3). The proposed model involves five cognitive elements (literacy skills, statistical knowledge, mathematical knowledge, context knowledge, and critical questions) and two dispositional elements (beliefs and attitudes and critical stance). 
More than ever, the reality likely to emerge after this severe global health and economic crisis may demand reflections on social data. Several authors also emphasize how social responsibility may and should be part of the teaching-learning concerns of statistics. Engel $(2014,2017)$ identifies the current times as promising more active citizens' participation, discusses the complexity of social and health phenomena represented in databases with multivariate structures, and presents examples of graphs that can help students understand the urgent problems of society. Engel et al. (2016) consider that knowledge and skills to reason adequately with data are an important prerequisite for the functioning of democracy in our mass societies and pursue a twofold pedagogical purpose: (1) to draw attention to the fact that monitoring progress with respect to fundamental rights requires, besides civil courage, critical thinking and commitment, and also quantitative skills in understanding and analyzing data, and (2) to give students a strong experience that statistics matters and statistical analyses play a role in understanding pressing social and political issues of our time.

In the same direction, Nicholson et al. (2018) discuss the use of civic statistics that includes data on current key social phenomena such as migration, demographic change, health, crime, employment, and poverty. The paper is based on the work of Pro Civic Statistics, a European project with six universities (Durham, Haifa, Ludwigsburg, Paderborn, Porto \& Szeged) that focuses on promoting civic engagement via exploration of evidence and on related challenges for statistics education (the paper also contains an appendix with class activities ).

The abovementioned articles (Engel, 2014, 2017; Engel et al., 2016; Nicholson et al., 2018) claim that the use of real databases to investigate aspects related to health, the environment or social justice, could motivate students to learn statistics. They further stress the importance to understand and analyze data for the building of a democratic society, considering that the ability to study evidence-based information would help in combating misinformation that often stems from fake news.

It is worth noting that data and chart analysis and interpretation may contribute to a worldwide broadening of literacy skills and lead to the incorporation of one of the main ideas of Brazilian educator Paulo Freire (Freire, 1987) into the concept of statistical literacy. In this sense, Weiland (2017) proposes an extension of Gal's definition in terms of critical statistical literacy. In his words:

... I would like to draw a connection between statistical literacy and critical literacy based around the notion of 'reading and writing the word and the world'. I propose that reading the word with statistics is partially what Gal (2002) describes as the reading context in statistical literacy. Furthermore, I propose writing the world with statistics is partially what Gal (2002) refers to as the enquiry context, focusing on the statistical investigative cycle, and in terms of the second component of his definition of statistical literacy (e.g., the ability to communicate reactions to and understanding of statistical information). I say partially because reading also refers to reading the world, or in other words, seeing the world through statistics. (p. 7)

Relate to teaching, Weiland (2017) emphasizes the importance of social issues discussions during statistics classes:

... I problematized traditional notions of statistical literacy to form a basis to propose a revised perspective of statistical literacy. From this perspective, it is crucial for students to have opportunities to tackle complex sociopolitical issues in conjunc- 
tion with learning powerful statistical concepts and practices in an effort to be able to read and write both the word and the world with statistics as critical citizens. (p. 13)

To make it clearer, Weiland (2017) previously pointed out that:

... I will refer to as a critical citizen, where citizens are empowered to participate actively in their community and/or government, and also interrogate the structures at play within their community and government that produce conditions of injustice, and actively work to change those that (re)produce injustices. (p. 3)

According to Sanders (2020), the COVID-19 pandemic has demonstrated the importance of statistical thinking and knowledge of variability and uncertainty. The author acknowledges the importance of reading and interpreting distribution charts and offers examples of how the need for such statistical thinking has emerged to help understand several issues pertaining to the current pandemic context.

In reference to charts, researchers have developed criteria for classroom teachers to be able to extract the greatest amount of correct information when reading and interpreting a chart. This requires their concernment with developing skills that involve the process of reading, analyzing, and interpreting information. Curcio (1989) outlines three levels which were extended later to a fourth level by Shaughnessy et al. (1996). An elaborate discussion about graph interpretation was provided by Friel et al. (2001), including identification of six behaviors associated with graph sense. In an excellent summary on graph interpretation, Shaughnessy (2007) argued that these six behaviors agree very well with Curcio's (1989) three levels and proposed two more, corresponding to the fourth level proposed later. In Table 1, based on the above references, we present the levels and the corresponding interpretation and behaviors associated with them. The levels correspond to an increasing understanding of graphs; however, some of the behaviors indicated in the table may be common to adjacent levels, varying only in intensity.

The examples and methodologies proposed by statistical educators may serve as a basis for the implementation of new classroom scenarios, in which students will be more open to activities that might help them further understand the harsh reality they have lived and still experience with the pandemic. A recent overview of statistical education research can be found in a book edited by Ben-Zvi et al. (2018b) that includes chapters on several methodological issues and that theoretically supports the area. For example, Chapter 16, in Design of Statistics Learning Environment (Ben-Zvi et al., 2018a), discusses the statistics learning environment. The word environment is used to mean that several factors must be considered in the learning process. Social, cultural, psychological, and pedagogical issues, among others, interacted to produce different situations in classroom, affecting students' development. To promote the central ideas in statistics and statistical literacy, these authors emphasized the necessity to reflect on the learning environment. In this way, to implement initiatives as we propose in this paper, it is convenient to reflect on the learning environment in which it will be used. To facilitate this reflection, they suggest considering six dimensions, briefly presented in Table 2 .

In Brazil, students learn statistics in elementary and secondary schools as part of the mathematics program. Regarding university education, statistics-related subjects are included in the syllabus of mathematics teaching degrees and several other university courses as well. The Brazilian community of statistics educators has been working to improve the understanding of statistics nationwide. In the next paragraphs, we mention some of the publications related to the present paper. 


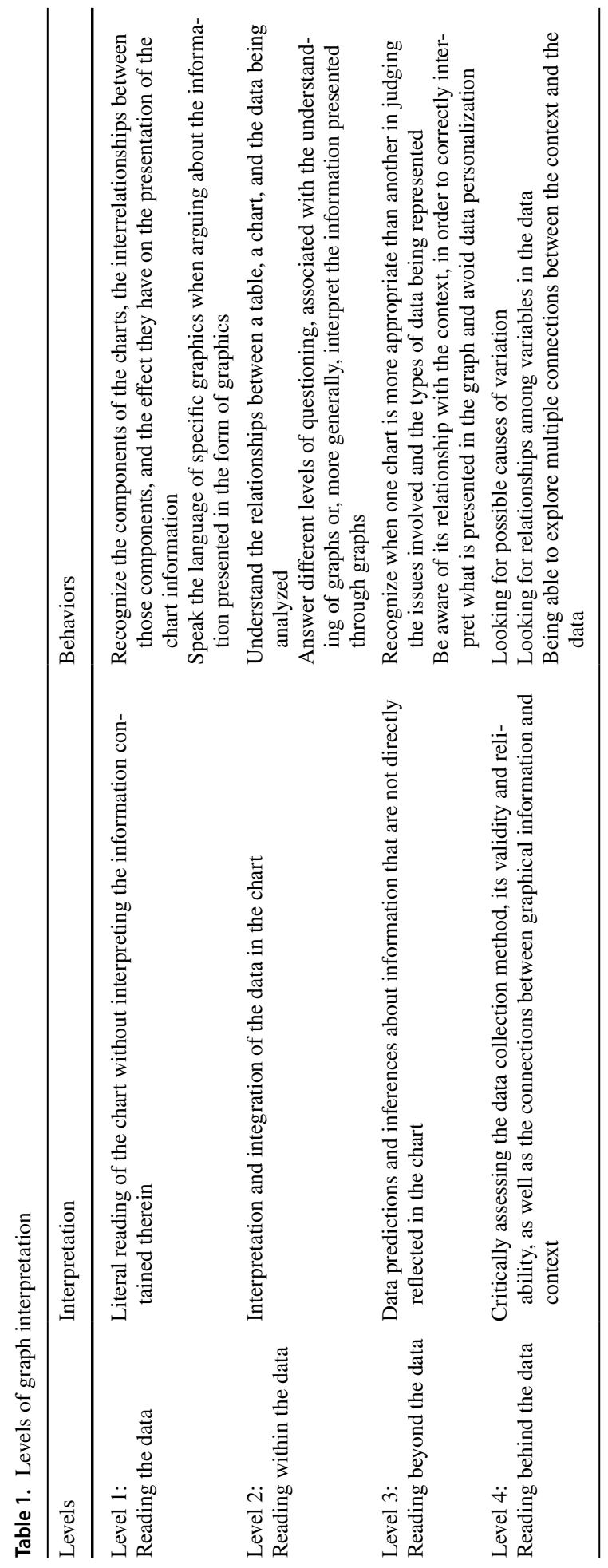


Table 2. Dimensions of statistics learning environment

\begin{tabular}{ll}
\hline Dimensions & Description \\
\hline $\begin{array}{l}\text { 1. Focus on central ideas } \\
\text { 2. Well-designed tasks }\end{array}$ & $\begin{array}{c}\text { Use key statistical ideas to establish goals to teaching } \\
\text { Design tasks to promote student collaboration and interaction, aiming to develop } \\
\text { central statistics ideas }\end{array}$ \\
$\begin{array}{l}\text { 3. Real or realistic data } \\
\text { Data is a central part of statistics learning. The related tasks must include experi- } \\
\text { ence with statistical ideas in real context }\end{array}$ \\
$\begin{array}{l}\text { 4. Technological tools } \\
\text { Used to perform calculations and data analysis, visualize graphs and concepts, } \\
\text { and perform simulations }\end{array}$ \\
$\begin{array}{l}\text { Build a classroom discourse with active students' participation to answer ques- } \\
\text { tions collaboratively by using statistical arguments } \\
\text { tor and evaluate }\end{array}$ & $\begin{array}{c}\text { Create assessments integrated with all activities of the course and the other } \\
\text { dimensions mentioned above }\end{array}$ \\
\hline
\end{tabular}

Several researchers have studied the development of projects that promote data collection and analysis done by students in either basic or higher education (e.g., Barberino \& Magalhães, 2016; Barbosa et al., 2019; Campos et al., 2011; Porciúncula \& Samá, 2015; Velasque et al., 2019). The act of collecting and analyzing one's own data and the execution of transversal and interdisciplinary curricula foster students' debate and expand the potential of statistics-related subjects to contribute to educating critical citizens. Particularly, regarding statistical literacy in the teaching of charts, Campos and Coutinho (2019) discussed an activity in a college level statistics introductory course. The students, working in groups, researched and critically analyzed charts published in the media. They were required to prepare a class presentation and a written report with their findings. Among other points, students identified problems with computations, labels, and scale. They also pointed out unclear and inadequate graphs representations. After the presentations by all groups, a class discussion was used to correct mistakes and to allow better understanding of the graphs analyzed. The authors conclude that the activity developed critical competence and statistical literacy in the students. Also, Andrade et al. (2020) developed a virtual activity about graph interpretation to complement classroom meetings in an introductory statistics course for undergraduate engineering students. The activity starts with an individual investigation on media graphics that contain some statistical manipulation. Next, each student shares the graph found, and the corresponding analyses, with the rest of the class. In addition, to promote collaboration, each student discusses at least one graph analyzed and shared by another student. In the paper, the authors present the analysis of the students' discussions and responses referring to three of the chosen charts. Andrade et al. (2020) conclude that the students developed statistical literacy and increased their critical analysis of graphs.

In this article, we follow Weiland's ideas (Weiland, 2017) on statistical literacy and critical citizenship. In this way, we use the pandemic to motivate reflections leading to critical statistical literacy. Furthermore, as per Sanders (2020), we consider the differences shown in graphs related to the pandemic as an opportunity to discuss several statistical issues, in particular variability, one of the fundamental ideas in statistics and an important aspect to build statistical literacy.

The theoretical framework that supported this article is composed of two interconnected paths. The first is related to the reading of reality through graphs of social data, providing the development of a critical citizen who understands the structures of society with a view 
of engagement and participation (e.g., Engel, 2017; Freire, 1987; Nicholson et al., 2018; Weiland, 2017). The second path relates to the activities needed to achieve a critical statistical development. For this, the use of statistics education methodologies, together with the graph reading levels (see Table 1), will allow a socially referenced understanding of concepts such as distribution, variability, scale change, moving average, and correlation.

\section{Examples of charts describing COVID-19 behavior}

Given the overload of available information on COVID-19, society is left with the arduous task of breaking down many terms and concepts with which they are unfamiliar, such as estimates, modelling, exponential growth, trends, rates, and indicators. These are fundamental concepts to answer questions related to the behavior of the number of confirmed cases and deaths. It is also important to assess the effects of isolation measures on the number of deaths, and how the decisions made by the authorities reflect on the charts. For instance, it is interesting to discuss whether a gradual return to normality, or more restrictive measures, has caused an effect of decreasing mortality and eliminating the risk of successive epidemic waves.

Much of the information about the pandemic is presented in charts of the most diverse formats, the most common being line charts for time series. This type of charts allows the description of behavioral observations over time for a series comparison, as well as assessing trends and atypical cases. In general, the vertical axis of the graph records the number of cases, cases per inhabitant, number of deaths, deaths per inhabitant, case estimates, and others. The horizontal axis commonly shows the date of the record, days after a certain number of notified cases, etc. Sometimes, the vertical axis is presented on a logarithmic scale. A very common way for television media to present the panorama of the epidemic in Brazil is through maps. The maps make it possible to analyze the data with the location where they occur. In particular, when analyzing epidemiological data, choropleth maps are used to represent in different colors numerical values related to geographic areas.

There will be a massive range of possibilities for statistics or even mathematics to work on the development of projects with students, and it is important that teachers plan the learning environment taking into account the dimensions presented in Table 2. In the next subsections, examples of charts with varying degrees of complexity will be presented. They illustrate how different graphical reading levels and behaviors associated with them, described on Table 1, can be explored by teachers in class. Particularly, it is important to promote class discussions to encourage students' participation and engagement in society, as proposed by several authors. We also consider that statistics education allows for a deeper understanding of how Brazilian inequality and regional diversity can help explain the behavior of high mortality rates due to COVID-19 in the country, thus contributing to the development of critical citizens.

\subsection{COVID-19 data chart comparing Brazil and other countries}

Many of the significant uncertainties regarding this pandemic and its future developments relate precisely to the need to improve the quality of information. During the COVID-19 pandemic, several organizations and media channels have been disseminating databases and information organized in tables or charts. Among them, particular attention is drawn to those belonging to health information systems of all countries, which are responsible for 
organizing, centralizing, and disclosing data on the pandemic as accurately and swiftly as possible. The Our World in Data ${ }^{1}$ portal of the University of Oxford seeks to understand the world's major problems and translate them into comprehensible information for nontechnical audiences. Among several initiatives, it provides data, visualization tools, articles, and reports on the COVID-19 pandemic. Among the visualization tools available in the portal, it is possible to find a variety of types of line charts and get answers on the current COVID-19 situation around the world. One can also compare the behavior of the epidemic in specific countries based on the analysis of the number of cases and deaths per million people, lethality rates, vaccination coverage, number of tests performed, and number of vaccinated individuals. During the preparation of the activity of reading and interpreting graphics, the teacher must consider, for example, the learning objectives to be achieved and how to encourage student participation.

A common question is how one can compare the performance of one country to another's. In this sense, Figs. 1 and 2, taken from the University of Oxford portal, compare Brazil and four other countries (UK, USA, Germany, and Israel). For class discussions with students, it is important to select countries that generate good comparison data with Brazil (so this choice is not unique). It is worth mentioning that such data is updated as of 31 December 2020.

Figure 1 shows the cumulative number of COVID-19 deaths per million people with the horizontal axis indicating the number of epidemic days, starting when the fifth death is reported (instant 0). Such standardization allows for a comparison of countries in a common time scale. In the vertical axis, Fig. 1a uses a linear scale, while Fig. 1b uses a logarithmic scale of the cumulative number of deaths per million people.

Figure 2 also has the number of epidemic days on the horizontal axis with the vertical axis showing the moving (or rolling) 7 days average of number of deaths in linear (Fig. 2a) and logarithmic scales (Fig. 2b). These moving average charts have been widely used by the media; they minimize fluctuations caused by, for example, the delay of death records on weekends. Figure $2 \mathrm{~b}$ properly shows, in a logarithmic scale, the behavior of the pandemic for countries with data in different orders of magnitude.

For both figures, the above descriptions related to the identification of the main elements that make up the charts correspond to Level 1 (reading the data) of graph interpretation. With respect to Level 2 (reading within the data), in Fig. 1a, three countries (USA, Brazil, and UK) show similar behavior and a high cumulative mortality rate by the end of 2020. The USA and the UK had more than 1,000 deaths per million inhabitants in December, whereas Israel and Germany had a rate of around 400 deaths per one million people. Figure 1b, on a logarithmic scale, allows for the identification of a death growth trend that is quite close among the five countries. Similar comments can be made about Level 2, for Fig. 2.

Continuing the analysis, related to reading beyond the data (Level 3), we can observe that line charts are appropriate to assess both the pattern and the trend of the epidemic. For example, we can discuss in class what to expect from the chart in future periods. In Fig. 1a, we can see the difference in mortality rates between countries and that all curves show a positive slope at the end of 2020, seeming to show a tendency of growth of this accumulated rate. With the change to a logarithmic scale, the differences in pattern between countries decrease and it is possible to infer certain stability at the end of

\footnotetext{
1 https://ourworldindata.org/about
} 
a Cumulative confirmed COVID-19 deaths per million people

Limited testing and challenges in the attribution of the cause of death means that the number of confirmed deaths may not be an accurate count of the true number of deaths from COVID-19.

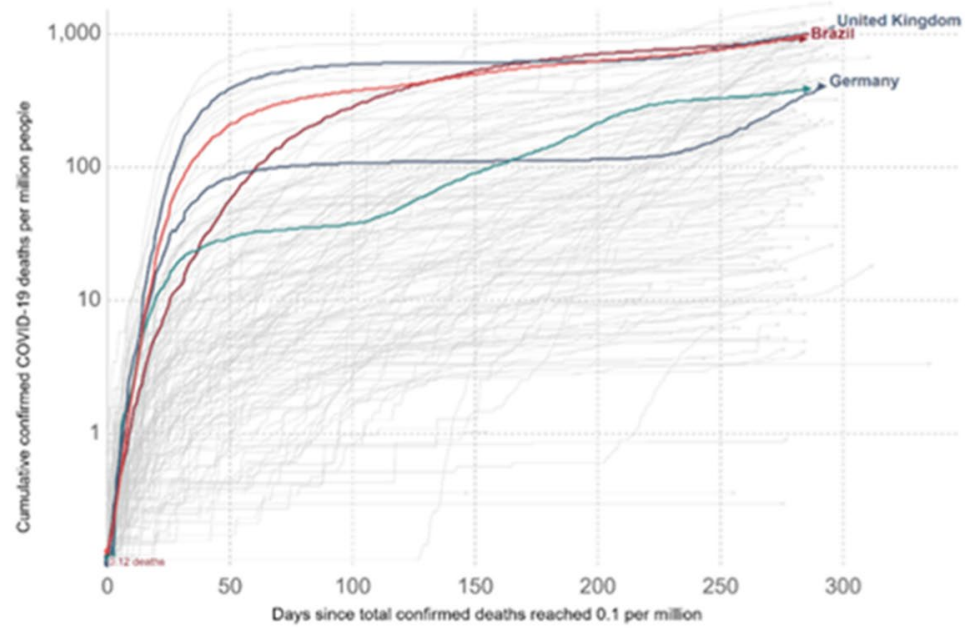

Continent

b Cumulative confirmed COVID-19 deaths per million people

Limited testing and challenges in the attribution of the cause of death means that the number of confirmed deaths may not be an accurate count of the true number of deaths from COVID-19.

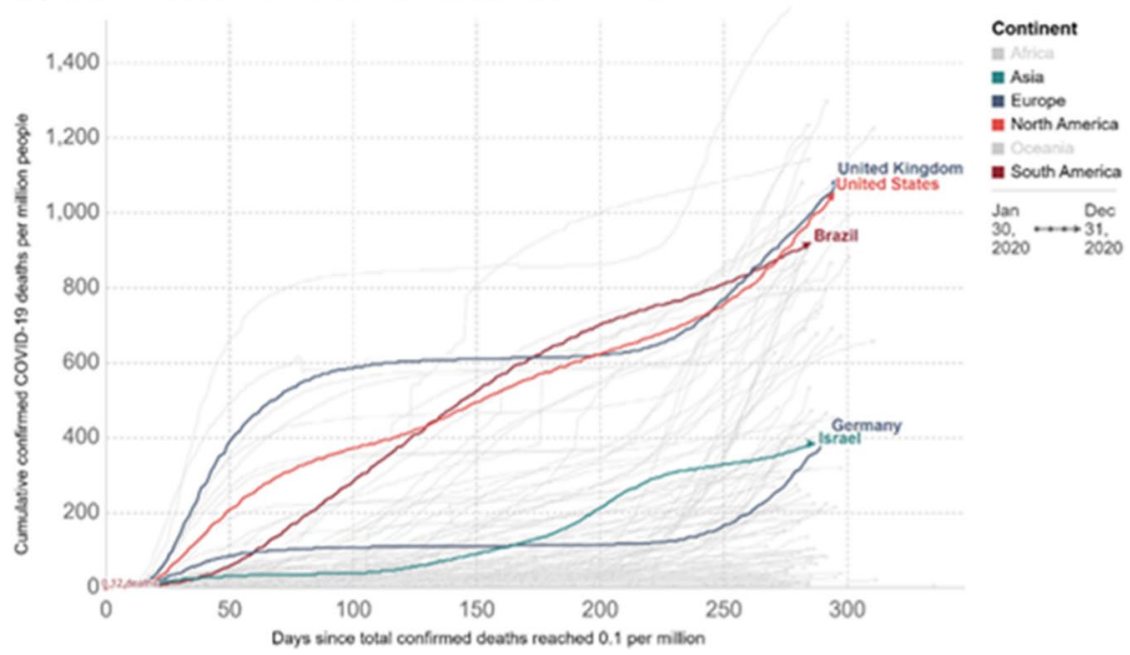

Fig. 1. Cumulative confirmed COVID-19 deaths per million people in some countries on a linear (a) or logarithmic scale (b). Source: https://ourworldindata.org/, licensed under CCBY

lines, except for Germany, which even on this scale still presents a positive slope. From Fig. $2 a$ and $b$, it is possible to assess the epidemic waves in each of the countries. In the classroom, students can make inferences about the severity of the pandemic for each country in different moments. For example, Brazil and the USA, unlike other countries, 
a Daily new confirmed COVID-19 deaths

Shown is the rolling 7-day average. Limited testing and challenges in the attribution of the cause of death means that the number of confirmed deaths may not be an accurate count of the true number of deaths from COVID-19.

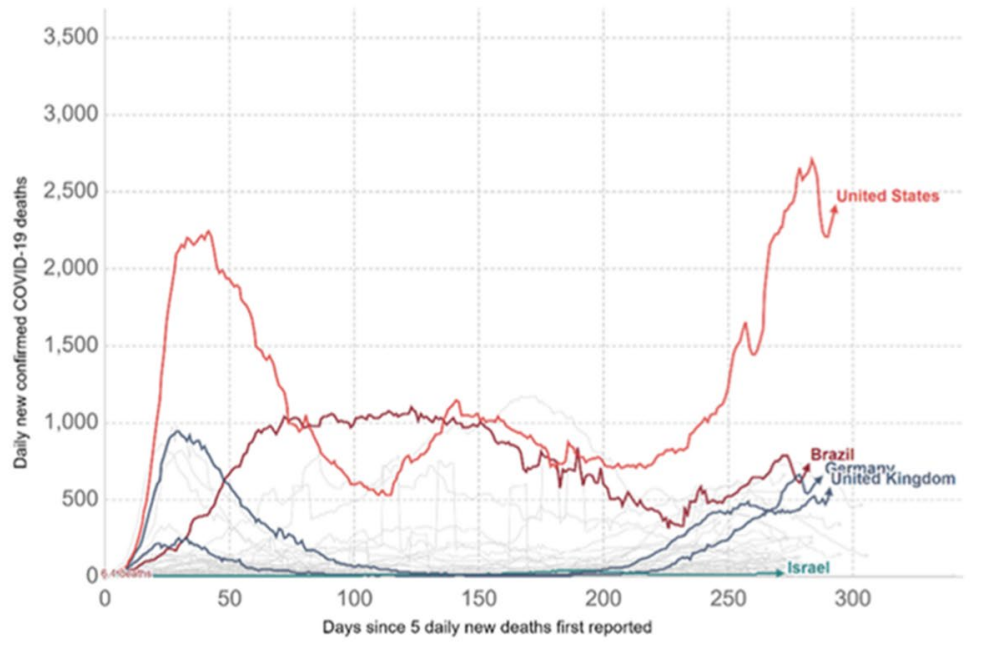

Continent

III Anica

- Asia

E Europe

ENorth America

Int Oceania

a South America

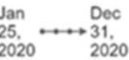

b Daily new confirmed COVID-19 deaths

Shown is the rolling 7-day average. Limited testing and challenges in the attribution of the cause of death means that the number of confirmed deaths may not be an accurate count of the true number of deaths from COVID-19.

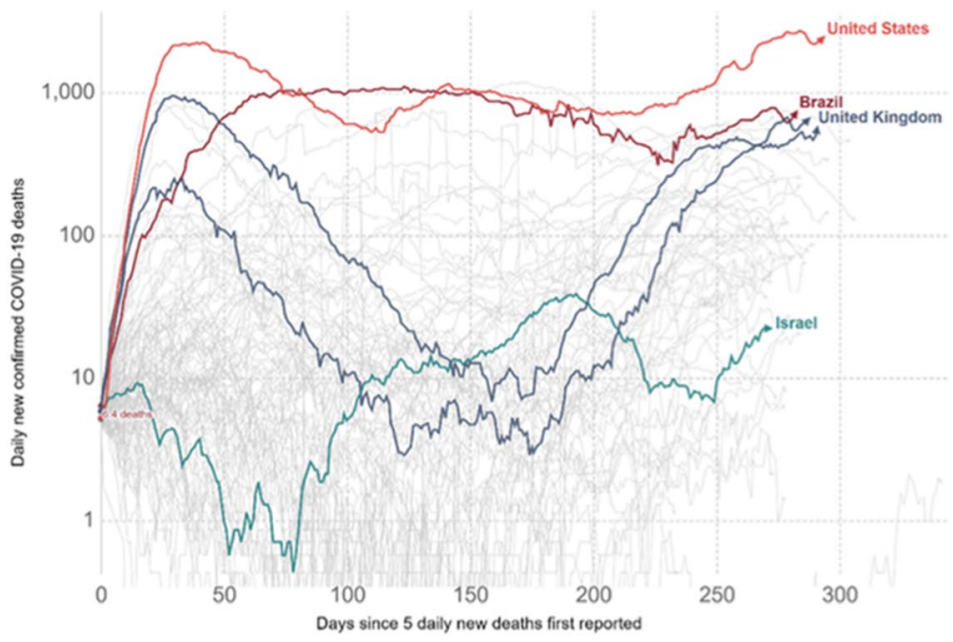

Continent

III Alrica

Asia

a Europe

E North America

In Oceania

a South America

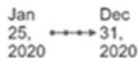

Fig. 2. Rolling (moving) average line chart of the evolution of COVID-19 deaths in some countries on a linear (a) or logarithmic scale (b). Source: https://ourworldindata.org/, licensed under CCBY

take a long time to reduce the number of daily deaths; in those countries, there was for many months a very high average, around 1,000 daily deaths.

At Level 4 (reading behind the data), when trying to read behind the data, the teacher can contextualize and discuss the effects of government policies on the behavior of this epidemic. For example, why the average number of deaths confirmed in Brazil had a slower 
growth in the beginning than that registered in the USA and the UK? It is also important to emphasize that an effective understanding of the results produced should consider different political, economic, and educational peculiarities, as well as local access to health, income distribution, and other characteristics that may influence the behavior of these curves. In the classroom, teachers should encourage the search for information about the policies carried out in each country to contain the epidemic, as well as the type of expected effect of each policy on the behavior of the curves. Data of this type can be obtained from official country information channels and international organizations such as the UN and WHO. It is also an opportunity to experiment with collaboration of teachers from other disciplines.

\subsection{Inequality charts in Brazil within the context of COVID-19}

As said earlier, Brazil is a large country, geographically and politically with 5570 counties. To apply public policies and collect social indicators, these counties are geographically aggregated into 558 micro-regions. The main factors used for these divisions are natural, social, economic, and political-administrative characteristics. Despite having a universal health system well spread throughout its territorial extension, Brazil was unable to implement measures in a coordinated way, which resulted in being included in the lists with the worst mortality indicators of the epidemic.

Figure 3a shows the map of Brazil separated by regions with white lines representing the states. The different colors represent the COVID-19-cumulated mortality rates per million inhabitants of each of the five regions; darker colors correspond to higher rates. Figure $3 \mathrm{~b}$ shows the COVID-19-cumulated mortality rate, divided by quintiles ( $20 \%$ total range fractions), for each of the 27 states with the white lines identifying the micro-regions. These comments correspond to Level 1 of graph interpretation (Table 1).

With a Level 2 graph reading, one observes in Fig. 3a that the Central-West region (composed of three states and the Federal District, where the country's capital Brasília is located) presents the highest mortality rate, while the Southeast region has the lowest. From Fig. 3b, the states in the southernmost region have the lowest death rates per million inhabitants; on the other hand, the highest rates, represented by the darker colors, are from two states in the North region, and one state and the capital located in the Central-West region.

Choropleth maps allow representations of values by areas such as regions (Fig. 3a) or federation units (Fig. 3b). This type of visual representation assumes that values are uniform (same color) within each area, and this is important to be highlighted in the classroom discussion. One possible way to explore the graph complexity that sometimes shows up is to ask the students about the different color settings in these two figures. In Fig. 3a, the colors represent regions (rates are provided in the key), while in Fig. 3b, they indicate different ranges of mortality rates in federation units. In addition, when reading and interpreting the maps, students could be asked whether socioeconomic differences may have influenced the results. Another interesting point to discuss relates to different choices of rate. For instance, what could we expect to happen if we consider the number of deaths by the number of households or by the number of adults in each area? Furthermore, students could also discuss the concept of spatial density of deaths based on the calculation of the number of deaths per hectare. The above comments would exemplify a Level 3 graphical analysis.

To reach the most advanced graph reading level (Level 4), one needs to make connections between graphical information and context. Thus, it is important to note that 
a

COVID-19 cumulated mortality rate per million inhabitants in the regions of Brazil

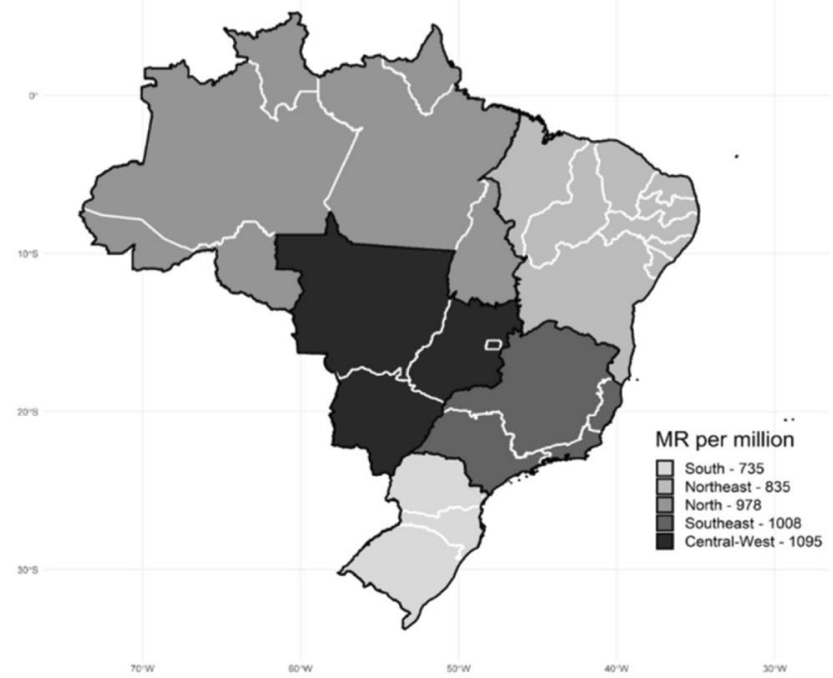

b

COVID-19 cumulated mortality rate per million inhabitants in the states of Brazil

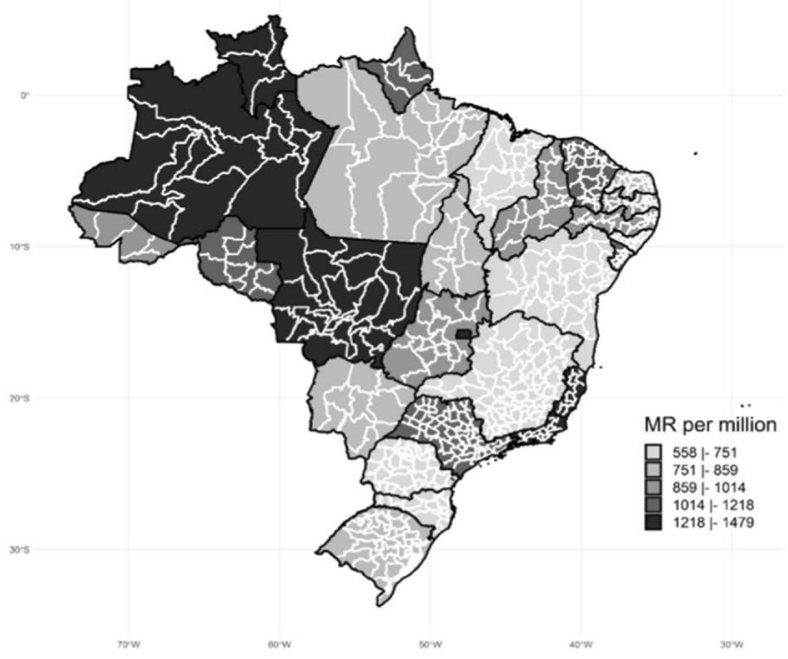

Fig. 3. Map with COVID-19-cumulated mortality rates per million inhabitants by regions (white lines representing the states) (a) and by states (white lines representing the micro-regions) (b). Source: authors with data available at https://covid.saude.gov.br/

Central-West is the second largest in territorial extension, the first one is the North region. Population in the Central-West region is concentrated in metropolitan zones, making rural areas sparsely inhabited. In addition, it has agriculture and livestock as its main economic activities. In the North region, the state of Amazonas is located, the 
largest inland area and almost entirely covered by the Amazon Forest, the largest tropical forest in the world.

To understand the excess mortality due to COVID-19 in Brazil and the reasons that led the disease to have mainly affected the most vulnerable populations, one needs to study the behavior of social indicators. In this way, the next figures show, for each region, the percentage of the population with an income lower than half the minimum wage (Fig. 4) and percentage of households with access to piped water (Fig. 5) organized by micro-regions.

A graphical analysis of Figs. 4 and 5 can start by recognizing the various measures present in a boxplot (Level 1). As indicated in Table 1, for Level 2, one can interpret the central tendency measures and the interquartile range. In both figures, it is possible to identify that the micro-regions of the North and Northeast regions are more vulnerable. From Fig. 4, most of these populations have an income of less than half the minimum wage. It can also be noted that at least half of the micro-regions of the North and Northeast had, respectively, $62 \%$ and $70 \%$ of their population in this poverty range. In addition, from Fig. 5, we infer that these two regions have the lowest ratios of households with water supplied through the general network.

When interpreting these figures on Level 3, in addition to drawing attention to the fact that this type of graph allows the comparison among groups with respect to position, symmetry, and variability of indicators, it is also important to point out that the regions behave very differently between them. In class, it could be discussed whether the regions could be grouped by similarity. From Fig. 4, students could identify a group with regions North and Northeast separate from the others. In Fig. 5, this separation may not be so evident. Note that, in both figures, the Central-West region is in an intermediate position despite having the highest mortality rate (see Fig. 3a).
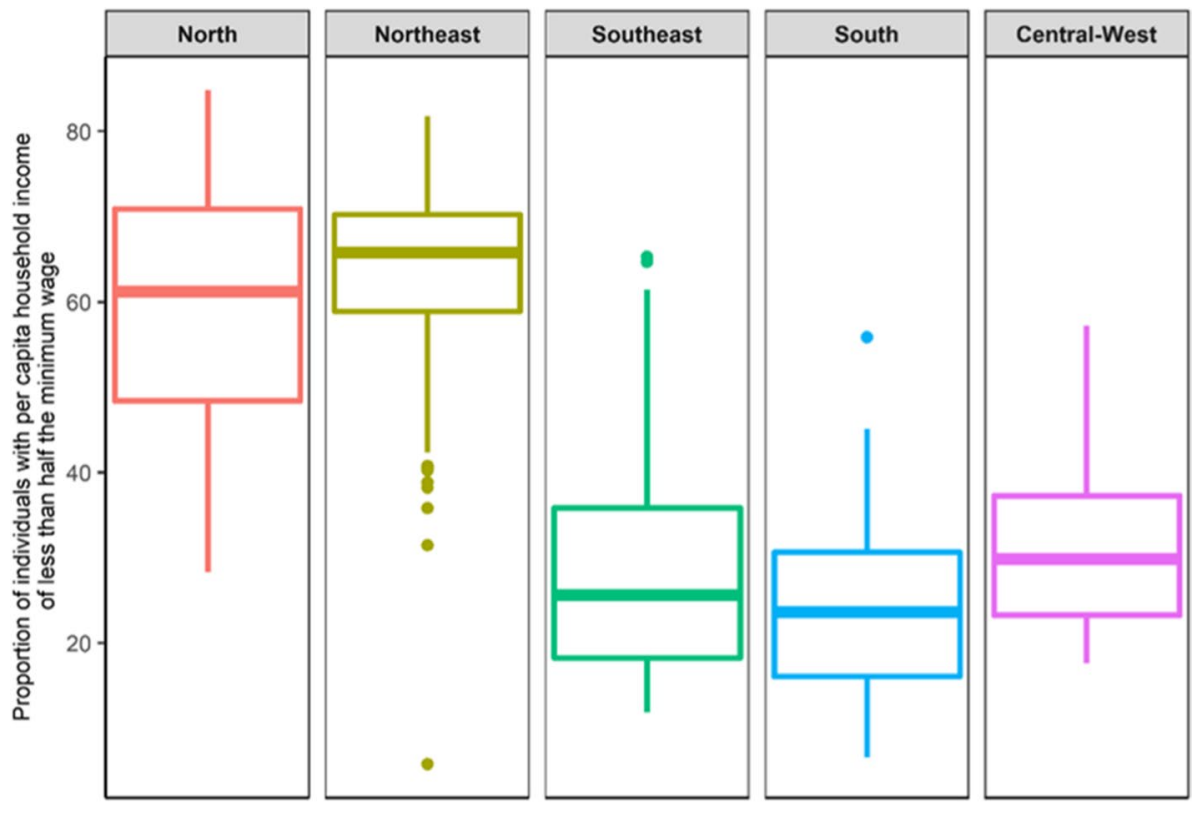

Fig. 4. Boxplot graph of the percentage of individuals with a per capita household income of less than half the minimum wage in the different micro-regions of each of the five Brazilian regions, in 2010. Source: authors with data from Population Census 2010, IBGE. 

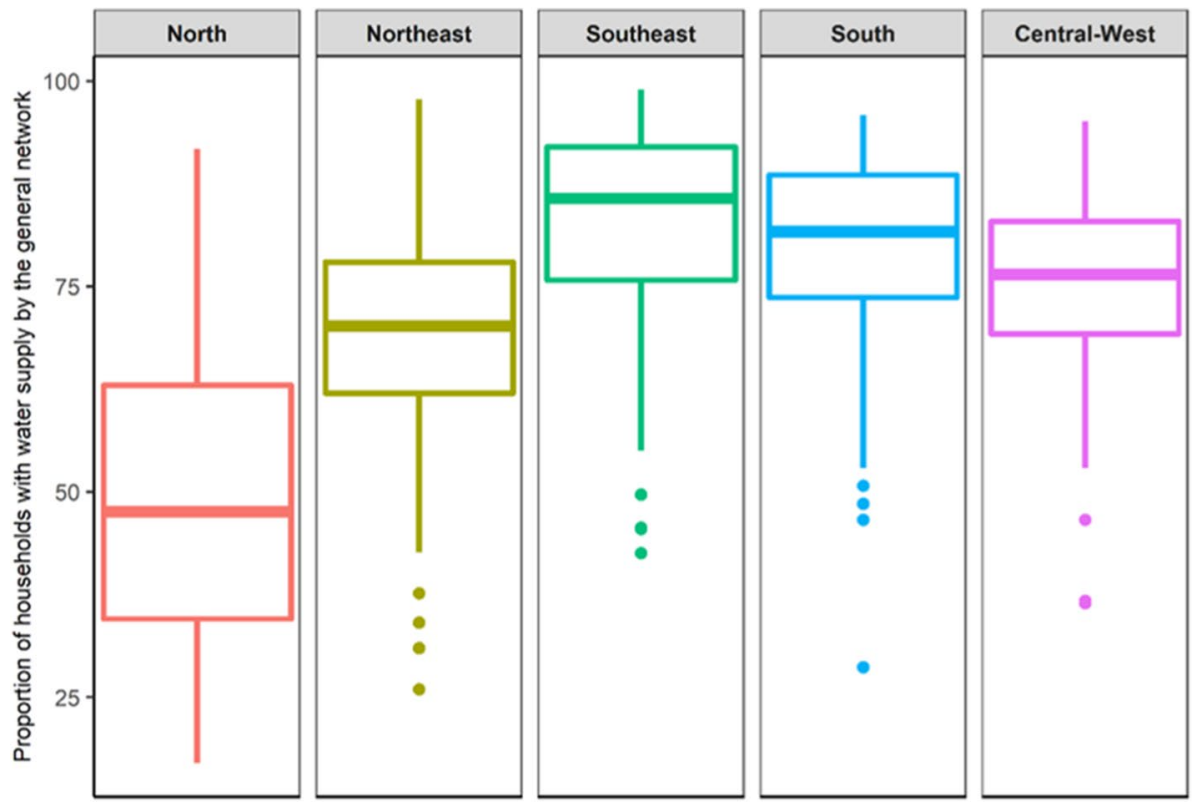

Fig. 5. Boxplot graph of the percentage of households with water supply by the general network in the different micro-regions of each of the five Brazilian regions, in 2010. Source: authors with data from Population Census 2010, IBGE.

For reading behind the data (Level 4, Table 1), one can study the variability between and within each region related to poverty and water supply indicators and their effects on dissemination and mortality by COVID-19. The importance of studying variability measures has been pointed out by statistics education; these graphs allow these concepts to be applied to the Brazilian reality. Also, it can be interesting to compare these data, which are about micro-regions and obtained from Census 2010 (latest available), with any other more up-to-date related information. One important data source can be PNAD (2020) which, despite not providing data on micro-regions, shows several indicators that can be used for comparison. For instance, with respect to Fig. 5, according to PNAD (2020), the situation remains mostly the same after 10 years, with only $59 \%$ of households in the North region having access to treated water.

In Fig. 6, the histograms show, by each region, the percentage of micro-regions according to the availability of hospital beds on the national unified health system (SUS) per 1,000 inhabitants. It is important to note that SUS beds, in general, serve the poorest population and that the data used in the histograms were obtained from the National Health Agency (ANS), an agency of the Ministry of Health. Thus, at Level 1 of reading graphs, it should be noted that the variable related to the number of SUS beds per inhabitant is shown on the horizontal axis, ranging from less than 1 bed to 5 or 6 beds per inhabitant. The height of the bars represents the percentage of micro-regions whose number of beds is classified in each interval.

For a Level 2 analysis of Fig. 6, reading within the data, it can be observed that there is great variability in all regions and a lag of most micro-regions in relation to the recommendations of the Ministry of Health, which is 2.5 beds per 1,000 inhabitants, marked by the dashed vertical line. Thus, it can be seen in Fig. 6 that the South region has the highest 

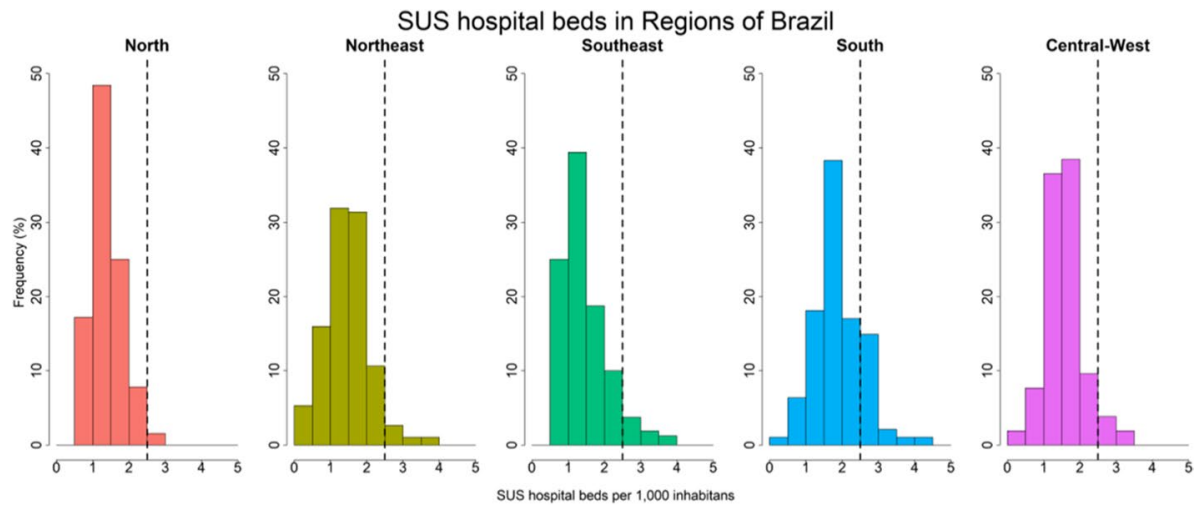

Fig. 6. Histogram of the number of SUS beds per 1,000 inhabitants in the five Brazilian regions, in April 2020. Source: authors with data from the National Health Agency, BR

concentrations above the recommendations of the Ministry of Health; on the other hand, the North Region has the largest number of micro-regions with hospital beds below the recommended level.

Following a description on Table 1, in Level 3 of graphical analysis, the histogram appears to be appropriate to represent the correspondent data because it allows observing which intervals have the highest and lowest quantities of micro-regions. Also, in the classroom, students can be encouraged to infer reasons that explain the differences between regions.

Level 4 of reading the data can be achieved with discussions on the requirements of special support for hospital beds (e.g., the need for respiratory support is about 5\%, according to the Ministry of Health). All these data help to understand the discrepancies in the lethality of the disease and in the distribution of mortality rates, and the need to strengthen the Unified Health System.

It is worth mentioning that the state of Amazonas, located in the Northern region of Brazil, was the first to declare the collapse of the health system. This region is precisely the one with the worst socioeconomic and health indicators (Figs. 4 and 5), the highest dependence on the Unified Health System, and the worst ratio of hospital beds per inhabitant (Fig. 6). For these reasons, the North region is highlighted in the next subsection.

\subsection{COVID-19 in the Northern region of Brazil}

We will present COVID-19 data for the Northern Region of Brazil and, based on graphs, we intend to evaluate potentially relevant geographic aspects. Therefore, this is an opportunity for students to discuss complex socio-political aspects while developing a critical statistical literacy, as defined by Weiland (2017). Information about the reality of territorial, social, and economic structures may help to explain how the characteristics of the occupation of the area are important to the understanding of the COVID-19 dynamics and, in this way, empower citizens in the search for their rights. Hence, it may be relevant to bring to the classroom the teachings of Milton Santos, a renowned Brazilian geographer and thinker, who brought innovation to the study of geography in Brazil. Santos and Silveira (2001) make a geographical interpretation of Brazil and propose categories of analysis that can help motivate the study of epidemic data contextualized in the territory. As an example, the concepts of density zones and rarefaction zones are highlighted there. The authors consider that the territory shows 


\section{COVID-19 mortality rate per million inhabitants in the micro-regions of the region North of Brazil}

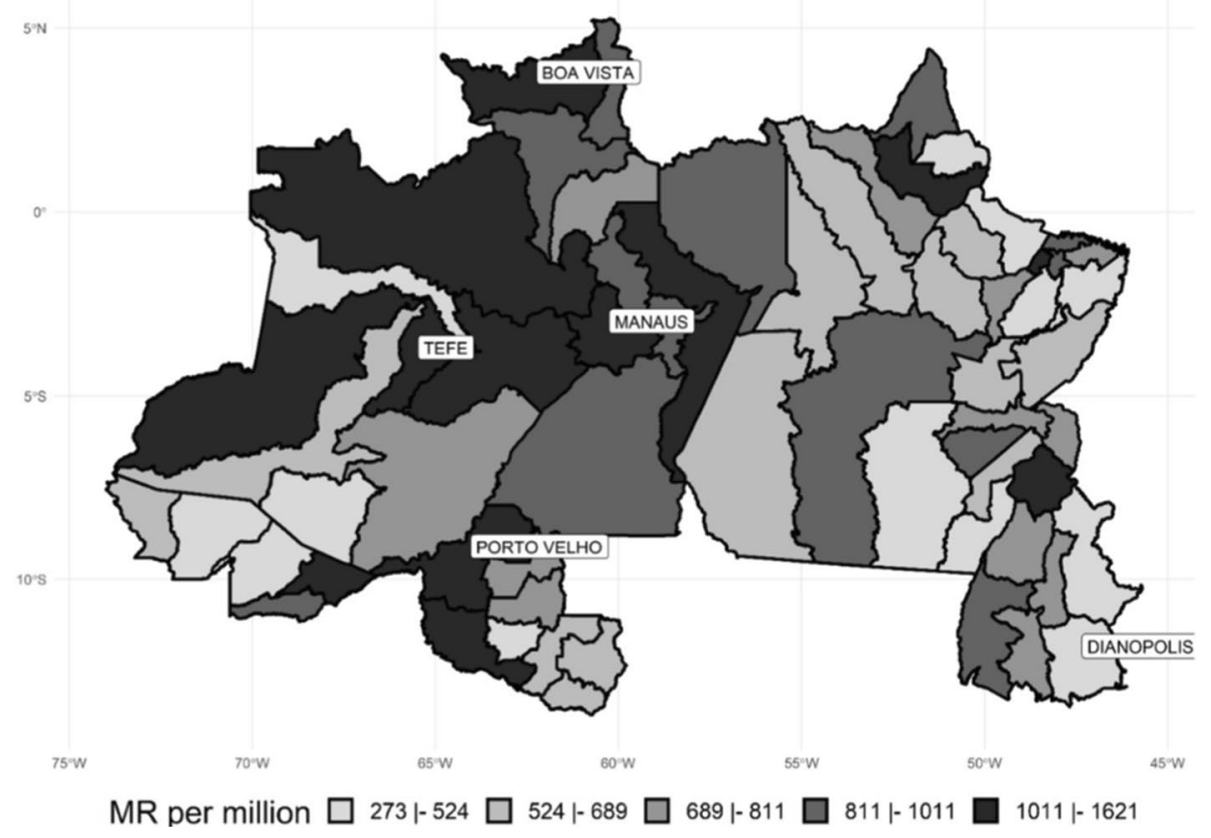

Fig. 7. Map with mortality rates per 100,000 inhabitants by the Northern region micro-regions. Source: authors with data available at https://covid.saude.gov.br/

differences in densities that cover different evolutionary processes. They also emphasize the importance of differentiating the density of people (demographic) from the densities of natural things (e.g., forests, vegetation, relief) and present several possibilities of indicators of density (urban density, rural density, productive density, employment density, consumption density, etc.). In addition to describing the reality of the epidemic in the Brazilian region with the most rarefied areas and with the highest density of forests, we also sought to relate the density of deaths by COVID-19 with the density of hospital beds in these micro-regions.

Brazil's Northern region is composed of seven states, Acre, Amapá, Amazonas, Pará, Rondônia, Roraima, and Tocantins (Fig. 3a), with a total area of 3,870,000 km², corresponding to $45 \%$ of the entire country. Despite its size, the region holds less than $9 \%$ of the Brazilian population, however heterogeneously distributed.

It is important to mention that population living on riverbanks, some of them composed of Indigenous peoples, live in isolation, with the rivers being the only transportation route for people and cargo. The National Indigenous Foundation (FUNAI) is a Brazilian government's agency whose mission is to protect and promote the rights of the country's Indigenous peoples; its website ${ }^{2}$ indicates, according the 2010 Census, that there are 305,873 Indigenous peoples in the region (almost 170 thousand only in the state of Amazonas). It is worth mentioning that the region has $37 \%$ of the total of the country's Indigenous inhabitants.

Figure 7 shows the map of the Northern region and its 64 micro-regions, with the colors representing COVID-19 death rate intervals per million inhabitants as of December 2020,

${ }^{2}$ http://www.funai.gov.br 
divided by quintiles. The values indicated in these rates were rounded up and the colors get darker as mortality rate is higher. The analysis above reflects Level 1 of graph readings (Table 1). These rates vary between 273 deaths per one million inhabitants in Dianópolis and 1,621 in Tefé. Additionally, there is a tendency to lower values in the east and higher values in the central and northwestern areas of the state (Level 2).

To reach Level 3 of graph reading, one needs to recognize, for example, that the microregions with higher mortality rates, between 1,011 and 1,621 deaths per one million inhabitants, are the same as those that, according to the 2010 census, had a high number of Indigenous inhabitants, such as Tefé, Manaus, Boa Vista, and Porto Velho. ${ }^{3}$ At the most advanced level, Level 4, one can observe that in these cities, Indigenous peoples have quite diverse living conditions; they may live in isolated groups in the forest or concentrate in small urban areas. Nevertheless, this population could be more vulnerable to infectious diseases. In general, the immune system of the isolated population tends to be weaker, and this population has less access to vaccines and healthcare assistance; on the other hand, the population living in the urban areas is more exposed to poverty. With all aspects and vulnerabilities considered, these groups are among those with a higher priority for getting the COVID vaccine in the country.

Clearly, statistical literacy focusing on the development of critical citizens needs to find ways to disseminate Brazil's statistics and data and have them studied.

\section{Final considerations}

Amidst the most severe health, social, and economic event of the last hundred years, the relevance of scientists and international organizations (United Nations, Organization for Economic Co-operation and Development, World Health Organization, etc.) became evident. The COVID-19 pandemic has required a major emergency effort from researchers around the world to understand the natural history of the virus, identify treatment options, and develop vaccines. How much can this pandemic serve as a motivation for societies to begin a process of transformation that takes them to another level of sustainability and solidarity? Statistics education can also play an important role as it can contribute to the formation of citizens who realize the need of urgent and profound changes in society.

The pandemic revealed how poverty and inequality in the world affect everyone. Furthermore, it demonstrated how some health systems and government policies were unable to protect their citizens from the disease. In fact, several issues such as over deforestation, inadequate land use, global warming, and disorderly and dense occupations of cities urgently need to be better understood. The population needs greater awareness of this reality and its consequences.

The tragedy of the COVID-19 pandemic pointed to a necessary and urgent discussion regarding the Health and the Millennium Development Goals set by the World Health Organization (United Nations, 2021), starting with those that specifically tackle healthcare. The tragedy also underscores the significance of universal healthcare coverage for the entire population, as advocated in the World Health Organization report (WHO, 2013). This document identified the need for national observatories and regional data-sharing centers to compile, analyze, and disseminate health-related indicators, thus reinforcing the importance of the widespread use of statistics and the need for its understanding by non-scientists.

$\overline{3}$ https://indigenas.ibge.gov.br/images/indigenas/mapas/pop_indigena_tot_2010.pdf 
The pandemic has placed these pressing issues in the global spotlight; it is worth noting that in Brazil, in addition to the examples mentioned earlier, a number of universities and professional associations have designed portals to concentrate information, including the list of ongoing research related to COVID-19. Apart from that, nongovernmental organizations and social movements have also created observatories and platforms to disseminate local or general information, seeking to increase awareness and adherence to measures to contain the spread of the virus and organize initiatives for local control or to demand governmental action.

In times of fake news and ideological debates that even deny science (Hallal, 2021), these civil society initiatives reinforced the guidelines of the World Health Organization regarding the urgency of restrictive measures aimed at holding off the peak of the epidemic curves and preventing or delaying the collapse of health systems. In order to convey these and other scientific concepts, charts presenting the most diverse events within the scope of the epidemic distributed in time or space have been produced to guide both crisis offices in monitoring and planning actions, and to explain to citizens how much and why restrictive health measures had become pressing.

The context of the pandemic will be present in people's hearts and minds for some time. This article used the reflections of Brazilian thinkers and authors of statistics education to highlight the importance and urgency for teachers to place the reality in the context of their classrooms. The graphic examples contained here help to reveal how a country, with such regional inequalities, produces different effects according to the regions and micro-regions. The availability of hospital beds was analyzed along with other aspects. In this way, the examples help to explain reality through data and can contribute to greater social engagement. It would not be too much to repeat that, in the current pandemic situation, one of the initial steps to be a critical citizen is recognizing that centralized government coordination, guided by science and a humanitarian perspective, would improve coping with COVID-19 in Brazil.

Every day, news about the pandemic exposed statistical aspects of literacy often discussed in disciplines related to statistics for professionals from various fields (mathematics, nursing, political science, medicine, biomedicine, biology, etc.), including future elementary and high school teachers. As already mentioned, the development of these school disciplines is conducive to the realization of projects, research actions, and methodologies with active engagement of students. More than ever, the subjects related to statistics are significant in the constitution of critical citizens who manage to assume collaborative, responsible, and solidary positions, supported by science and a collective perspective.

Data and materials availability All material and web-links used are available in the text.

Code availability Not applicable

\section{Declarations}

Conflict of interest The authors declare no competing interests. 


\section{References}

Andrade, F. C., Schiller, C. V., Silva, D. A. F., Menezes, L. P., \& Silva, A. S. (2020). Aspectos da interpretação de gráficos de estudantes universitários em um ambiente virtual (Aspects of university students' graph sense in a virtual learning environment). Bolema, 34(67), 462-479. https://doi.org/10.1590/ 1980-4415v34n67a06

Bakker, A., \& Wagner, D. (2020). Pandemic: Lessons for today and tomorrow? Educational Studies in Mathematics, 104(1), 1-4. https://doi.org/10.1007/s10649-020-09946-3

Barberino, M. R. B., \& Magalhães, M. N. (2016). Aprendizagem de estatística por meio de projetos no ensino médio da escola pública (Teaching statistics through projects at public high school). Educação Matemática Pesquisa, 18(3), 1223-1243.

Barbosa, M. T. S., Ross, S. D., Simões, B. F., Velasque, L. D. S., da Silva, A. S., Assunção, M. B. M., \& Tuttman, M. (2019). Educação estatística com formação cidadã em uma pesquisa quanti-ação no ensino superior (Education statistics with citizen training in quanti-action research in higher education). Revista de Ensino de Ciências e Matemática, 10(6), 114-125. https://doi.org/10.26843/rencima. v10i6.1463

Ben-Zvi, D., Gravemeijer, K., \& Ainley, J. (2018a). Design of statistics learning environments. In D. Benzvi et al. (Eds.), International handbook of research in statistics education (pp. 473-502). Springer.

Ben-Zvi, D., Makar, K., \& Garfield, J. (2018b). International handbook of research in statistics education. Springer. https://doi.org/10.1007/978-3-319-66195-7

Campos, C. R., Wodewotzki, M. L. L., \& Jacobini, O. R. (2011). Educação estatística - Teoria e prática em ambientes de modelagem matemática (Statistical education - Theory and practice in mathematical modeling environments). Autêntica.

Campos, C. R., \& Coutinho, C. Q. S. (2019). A modelagem matemática e o letramento estatístico no ensino de gráficos (Mathematical modelling and statistical literacy in the teaching of graphs). Revista Eletrônica de Educação Matemática, 14, 1-20. https://doi.org/10.5007/1981-1322.2019.e62726

Curcio, F. R. (1989). Developing graph comprehension. Elementary and middle school activities. National Council of Teachers of Mathematics.

Engel, J. (2014). Open data, civil society, and monitoring progress: Challenges for statistics education. In K. Makar, B. de Sousa, \& R. Gould (Eds.), Sustainability in statistics education. Proceedings of the Ninth International Conference on Teaching Statistics (ICOTS9, July, 2014), Flagstaff, Arizona, USA. International Statistical Institute iase-web.org [@ 2014 ISI/IASE] https://iase-web.org/icots/9/proceedings/ pdfs/ICOTS9_4F4_ENGEL.pdf

Engel, J., Schiller, A., Frischemeier, D., \& Biehler, R. (2016) Statistics education and monitoring progress towards civil rights. In J. Engel (Ed.), Promoting understanding of statistics about society. Proceedings of the Roundtable Conference of the International Association of Statistics Education (IASE), July 2016, Berlin, Germany. C2016 ISI/IASE. http://iase-web.org/documents/papers/rt2016/Engel.pdf

Engel, J. (2017). Statistical literacy for active citizenship: A call for data science education. Statistics Education Research Journal, 16(1), 44-49.

Freire, P. (1987). Pedagogia do oprimido (Pedagogy of the Oppressed). Paz e Terra.

Friel, S., Curcio, F., \& Bright, G. (2001). Making sense of graphs: Critical factors influencing comprehension and instructional implications. Journal for Research in Mathematics Education., 32(2), 124-158. https://doi.org/10.2307/749671

Gal, I. (2002). Adults' statistical literacy: Meanings, components, responsibilities. International Statistical Review, 70, 1-25. https://doi.org/10.1111/j.1751-5823.2002.tb00336.x

Hallal, P. C. (2021). SOS Brazil: Science under attack. The Lancet, 397(10272), 373-374. https://doi.org/10. 1016/S0140-6736(21)00141-0

Nicholson, J., Gal, I., \& Ridgway, J. (2018). Understanding civic statistics: A conceptual framework and its educational applications. A product of the ProCivicStat Project. Retrieved August 30, 2021 from: http://IASE-web.org/ISLP/PCS

PNAD. (2020). Pesquisa Nacional por Amostra de Domicílios Contínua PNAD contínua (Continuous National Household Sample Survey PNAD). IBGE. https://biblioteca.ibge.gov.br/visualizacao/livros/ liv101707_informativo.pdf

Porciúncula, M. M. S., \& Samá, S. (2015). Projetos de aprendizagem: Uma proposta pedagógica para a sala de aula de estatística (Learning projects: A pedagogical proposal for the statistics classroom). In S. Samá \& M. M. S. Porciúncula (Eds.), Educação estatística: Ações e estratégias pedagógicas no Ensino Básico e Superior. (Statistical education: Pedagogical actions and strategies in Basic and Higher Education) (pp. 133-141). PR: CRV.

Ranzani, O. T., Bastos, L. S. L., Gelli, J. G. M., Marchesi, J. F., Baião, F., Hamacher, S., \& Bozza, F. A. (2021). Characterisation of the first 250000 hospital admissions for COVID-19 in Brazil: A 
retrospective analysis of nationwide data. Lancet Respir Med. https://doi.org/10.1016/S2213-2600(20) 30560-9

Sanders, N. (2020). Can the coronavirus prompt a global outbreak of "Distributional Thinking" in organizations. Harvard Data Science Review, 2(2), 1-25. https://doi.org/10.1162/99608f92.a577296b

Santos, M. \& Silveira, M. L. (2001). O Brasil: Território e sociedade no início do século XXI (Brazil: Territory and society at the beginning of the 21 st century). Editora Record.

Shaughnessy, J. M. (2007). Research on statistical learning and reasoning. In F. K. Lester (Ed.), Second handbook of research on mathematics teaching and learning (pp. 957-1009). Information Age Publishing.

Shaughnessy, J. M., Garfield, J., \& Greer, B. (1996). Data Handling. In A. J. Bishop, K. Clements, C. Keitel, J. Kilpatrick, \& C. Laborde (Eds.), International Handbook of Mathematics Education. Kluwer International Handbooks of Education, 4. Springer. https://doi.org/10.1007/978-94-009-1465-0_7

Szwarcwald, C. L., Júnior, P. R. B. S., Marques, A. P., Almeida, W. S., \& Montilla, D. E. R. (2016). Inequalities in healthy life expectancy by Brazilian geographic regions: Findings from the National Health Survey, 2013. International Journal for Equity in Health, 15, 145. https://doi.org/10.1186/ s12939-016-0432-7

The Lancet. (2020). COVID-19 in Brazil: "So what?". In The Lancet (Vol. 395, Issue 10235, p. 1461). Lancet Publishing Group. https://doi.org/10.1016/S0140-6736(20)31095-3

United Nations. (2021). We can end poverty: Millennium development goals and beyond 2015. https://www. un.org/millenniumgoals/bkgd.shtml

Velasque, L. S., Silva, A. S., \& Barbosa, M. T. S. (2019). A pesquisa quanti-ação como ferramenta para o ensino de estatística na educação básica (The quanti-action research as a tool for teaching statistics in basic education). Revemat: Revista Eletrônica de Educação Matemática, 14, 1-16. https://doi.org/10. 5007/1981-1322.2019.e62828

Weiland, T. (2017). Problematizing statistical literacy: An intersection of critical and statistical literacies. Educational Studies in Mathematics, 96(1), 33-47. https://doi.org/10.1007/s10649-017-9764-5

WHO (2013). Pesquisa para cobertura universal de saúde. Relatório Mundial de Saúde (Research for universal health coverage. World Health Report). World Health Organization. https://apps.who.int/iris/ bitstream/handle/10665/85761/9789248564598_por.pdf;jsesionid=F57BD72B68F1CD7602BAAF170 A22B $2 \mathrm{AE}$ ? sequence $=26$

Publisher's note Springer Nature remains neutral with regard to jurisdictional claims in published maps and institutional affiliations. 